\title{
Biological constraints revisited: A critique
}

\author{
ERNEST N. DAMIANOPOULOS \\ VA Medical Center, Syracuse, New York
}

\begin{abstract}
Four types of supporting evidence for inferences of biological constraints on conditioning are evaluated: (1) unexpected failures to condition (discriminative leverpress avoidance); (2) rapid or one-trial learning (taste-aversion studies); (3) crossover learning effects (the Garcia-Koelling effect); and (4) unique predictions from biological constraint-based frameworks. According to a current logic model of scientific explanation and prediction, none of these types of evidence is adequately compelling for inferences of biological constraints. The core problem identified is that negative evidence not attributable to an identified causal factor in terms of $\mathrm{E} / \mathrm{C}$ (experimental/control) design outcome has been used to both reject general-process learning laws and compel inferences of biological constraints. A design solution using a blocking $\mathrm{E} / \mathrm{C}$ conditioning paradigm is presented.
\end{abstract}

Revolutionary advances in science have been attributed to shifts in investigative paradigms (Kuhn, 1962). In the field of learning, the discovery of biological constraints, primarily based on CS-US (conditioned stimulus-unconditioned stimulus) interactions (or crossover effects) promised such a shift. The basic finding, an easy association of CS1 with US1 (through Pavlovian conditioning) and of CS2 with US2, but not of CS1 with US2 or of CS2 with US1 (Garcia \& Koelling, 1966), led to a revolutionary shift in the emphasis of learning psychology away from learning principles and general-process laws of conditioning to more biologically oriented studies of learning (Bolles, 1970; Garcia, McGowan, \& Green, 1972; Rozin \& Kalat, 1971; Shettleworth, 1972; Timberlake \& Grant, 1975). The basic finding was intensely scrutinized by both proponents and opponents, who demonstrated it under different conditions and analyses of alternative interpretation, and showed it to be quite robust (Domjan, 1985).

The additional empirical evidence in support of biological constraint inferences that is emerging from the numerous research efforts of both proponents of biological constraints and their antagonists (see Domjan, 1983; Domjan $\&$ Galef, 1983, for a critical review) can be conveniently subdivided into four categories: (1) unexplained failures to learn that violate learning laws of association (e.g., discriminative leverpress avoidance); (2) unexpected cases of accelerated learning, again unexplained by the existing laws of association (e.g., taste-aversion conditioning); (3) interactional CS-US or crossover effects that violate the law of equipotentiality (e.g., the Garcia and Koelling effect; see Garcia \& Koelling, 1966); and (4) unantici-

I am indebted to Robert J. Carey (VA Hospital, Syracuse, NY 13210) and to Michael Domjan (Department of Psychology, University of Texas at Austin, TX 78712) for their suggestions and critical reading. Correspondence may be addressed to Ernest N. Damianopoulos, Research Service-151, VA Medical Center, 800 Irving Avenue, Syracuse, NY 13210. pated cases of specialized learning or unique effects outside the laws of learning (see, e.g., Daly, Rauschenberger, $\&$ Behrends, 1982). These four areas include the core phenomena that seem to warrant inferences of biological constraints.

One feature shared by the findings in these four areas is that which, according to Domjan and Galef (1983), establishes the presence of a biological constraint or, at least, provides sufficient grounds for doing so: the contradiction, by observed data, of expectations based on a relevant learning principle or general-process law. Put simply, the characteristic in common is the observation of negative data in an empirical test of a learning principle or a general-process law (e.g., the law of acquisition), which can either take the form of a failure to learn (Cases 1 and 2 above) or appear as an effect opposite to or unique in relation to expectations based on a learning law or laws (Cases 3 and 4). However, seen in this manner, the core behavioral phenomena that collectively present negative data with respect to extant general-process laws are neither sufficient nor compelling for inferences of biological constraints, because recent analyses and models of scientific explanation (e.g., Grunbaum, 1969; Harre, 1970; Hesse, 1974) indicate that negative data are no longer to be considered compelling enough to falsify a theory, law, or hypothesis that is being tested. Instead, they throw into question the special assumptions and procedures that led to the negative data in the first place.

The present critique addresses this problematic aspect of inferring the presence of biological constraints on the basis of negative data that seems to contradict an applicable learning law. It shows, for each of the four categories of evidence above, that the existing data, without certain further observations, do not provide sufficient grounds for inferentially identifying biological constraints. More specifically, the four categories of evidence used as inferential grounds for identifying biological constraints are critically examined for: (1) inferential adequacy of conclusions drawn from cited investigations; and (2) iden- 
tification of paradigms and types of observations needed to make such inferences of biological constraints necessarily compelling. To do this adequately it will be necessary to present a recent analysis of scientific explanation (i.e., Grunbaum, 1969), which reveals the particular model of logic that negative data outcomes in tests of a theory, law, or hypothesis exemplify. Added to this will be an analysis of the logic model embedded in E/C (experimental and control treatment) designs, in order to identify two types of negative data, only one of which can be used in the manner in which biological constraints proponents have phrased their arguments for biological constraints and against learning principles and general-process laws.

\section{Logic Models of Scientific Explanation}

The critique of biological constraint inferences is based on the application of logic models of scientific explanation and experiment. Thus, a word or two will be needed to establish the ground rules for determining the inferential adequacy of alleged demonstrations of biological constraints. The short sketch below introduces the covering law model of Hempel (1963), as well as the more recent model of Grunbaum (1969) with which the critique will be carried out.

Current philosophy of science analyses of negative or null results: The Hempel and Grunbaum models. In the philosophy of science, one current conception of scientific explanation, confirmation, and disconfirmation identifies three requirements for an adequate explanation: (1) an appeal to an applicable law of science; (2) the establishment of initial concrete test conditions, as determined by the operational and coordinative definitions of the abstract concepts and terms of the applicable law; and (3) the observation of the event predicted by the law (Hempel, 1963). The predicted event, if it occurs, confirms the law; if it does not, it disconfirms it. This has come to be known as Hempel's (1963) covering law model of scientific explanation and prediction.

According to this model, failures to condition, as in rat leverpress discriminative avoidance (Bolles, 1970; D'Amato \& Schiff, 1964), meet Requirements 1 and 2; but, of course, the expected event (Requirement 3) fails to occur. Given Hempel's covering law model, clearly the inference of falsification of the law-in this case the law of acquisition-is justified, and an inference of a "limitation" on the generality of the given process-law (Seligman, 1970) appears to be a particularly modest conclusion. This widely accepted view of scientific explanation (see, e.g., McGuigan, 1983) has been challenged by Grunbaum (1969) and others (Harre, 1970; Hesse, 1974); they object in particular to the entailment of disconfirmation by a failed prediction.

Grunbaum (1969) conceptualizes the relation of a theory $(T)$, a hypothesis $(H)$, the empirical assumptions $(A)$ needed in any actual test of $\mathrm{H}$, and the empirically observable consequences ( $\mathrm{C} 1$ and $\mathrm{C} 2$ ), as follows:

$$
\mathrm{T}(\mathrm{H} . \mathrm{A}) \rightarrow(\mathrm{C} 1 . \mathrm{C} 2) .
$$

Here, a theory, $\mathrm{T}$, includes the hypothesis $\mathrm{H}$ and the empirical assumptions A needed in any actual test of $T$. The theory $\mathrm{T}$ as interpreted by the conjunction $(\mathrm{H} . \mathrm{A})$, logically implies $(\rightarrow)$ the empirical consequences $\mathrm{Cl}$ and $\mathrm{C} 2$ through the assumptions and rules of inference embedded in the theory. Given that theory $\mathrm{T}$ is true, or in fact that the proposition $\mathrm{T}(\mathrm{H} . \mathrm{A}) \rightarrow(\mathrm{C} 1 . \mathrm{C} 2)$ is true, this means that it is not the case that theory $\mathrm{T}$, in the form of $(\mathrm{H} . \mathrm{A})$, is true and that observations $\mathrm{C} 1$ and $\mathrm{C} 2$ can fail to occur. A true theory cannot have false consequences. Thus, the observation of negative evidence, $-(\mathrm{Cl}$. C2), implies that (H.A) is false-that is, either $\mathrm{H}$ or $\mathrm{A}$ is false, or both. This being the case, negative evidence does not automatically (deductively) imply that $H$ is false, because such a conclusion can only be made if it can be shown that the test conditions $A$ do not rest on false empirical assumptions, or that they are, in a word, adequate. To reject $\mathrm{H}$ as false in a test of theory $\mathrm{T}$ thus depends on the degree of inductive evidence that supports A, which of course can never be complete. Although Hempel's covering law model is still correct in the assumption that true theories, hypotheses, and laws being tested cannot imply false consequences (i.e., negative data), nevertheless, as Grunbaum (1969) clarifies, negative data are not equivalent to false consequences. To demonstrate the latter, negative data must be independently demonstrated as being not due to false or inappropriate test assumptions (e.g., inadequate experimental design, inappropriate response-measurement operations, or inadequate CS and US parameter values). In summary, according to Grunbaum's model, negative evidence in any given test of hypothesis $\mathbf{H}$ or theory $\mathrm{T}$ does not deductively entail rejection of the hypothesis tested or the theory that entails it as being false (see also Harre, 1970; Hesse, 1974).

One criticism of this analysis might be that positive data similarly cannot be used to support a theory $T$ that is being tested, because positive data may be due to some factor in the special assumptions (A) surrounding the test rather than the designated active factor included in hypothesis $\mathrm{H}$; thus the argument above may be stood on its head. That this is not the case will be illustrated below by analyzing and identifying the logic model embedded in the $\mathrm{E} / \mathrm{C}$ design, which represents the general case in all psychological experimentation.

\section{E/C Designs and Positive and Negative Data}

The issue of any psychological experiment can be presented in terms of three types of evidence: (1) positive evidence; (2) negative evidence due to an unknown factor; (3) negative evidence due to a known, identified, and manipulated factor. To understand why the argument above about negative evidence cannot be stood on its head in relation to positive evidence, it is necessary to understand the distinctions among these three types of evidence in an actual case in which the $\mathrm{E} / \mathrm{C}$ design is employed.

Positive evidence. The E/C design, conventionally understood as incorporating a contrast between an ex- 
perimental (E) and a control (C) treatment, can be analyzed as follows:

$$
\begin{aligned}
& E:(X . A) \rightarrow(L, \bar{L}) \\
& C:(\bar{X} . A) \rightarrow(L, \bar{L})
\end{aligned}
$$

Above, $\mathrm{X}$ stands for the factor manipulated and $\mathrm{A}$ stands for the control treatment conditions, which include all the special conditions A that are needed in an experimental test of X's causal efficacy that in a learning experiment can lead to learning, $L$, or no learning, $\bar{L}$. Generalized, the results of any experiment will turn out as those shown at the top of Table 1. Table 1 also shows the possible inferences that can be made from the various types of results that can issue from an experimental test. As can be seen from Table 1, only Case 1 allows causal efficacy to be attributed to an experimentally manipulated factor $\mathrm{X}$. Case 2's results allow attribution of positive results to either $\mathrm{X}$ or $\mathrm{A}$; they are thus uninterpretable, because $\mathrm{A}$ stands for an indefinite number of factors (boundary conditions plus extraneous variables). Thus, although an argument for positive results can be criticized as being ambiguous with respect to the attribution of observed effects when the results for the $E$ and $C$ treatments are both positive (Case 2), nevertheless such criticism does not apply to positive results where the experimentally manipulated factor is shown to be both sufficient and necessary (Case 1; see Damianopoulos, 1982, 1987). Thus, the argument as presented by Grunbaum's (1969) analysis cannot be stood on its head when applied to positive results in Case 1, although such criticism may be valid when ap-

Table 1

\begin{tabular}{|c|c|c|c|c|c|}
\hline \multicolumn{3}{|c|}{ Case 1} & \multicolumn{3}{|c|}{ Case 2} \\
\hline & \multirow{3}{*}{$\begin{array}{c}\Delta \mathrm{R} \\
\times\end{array}$} & \multirow[t]{2}{*}{$\overline{\Delta \mathrm{R}}$} & \multicolumn{2}{|r|}{$\Delta \mathbf{R}$} & \multirow[t]{2}{*}{$\overline{\Delta \mathbf{R}}$} \\
\hline $\mathrm{E}$ & & & E & $x$ & \\
\hline $\mathrm{C}$ & & $\times$ & $\mathrm{C}$ & $\times$ & \\
\hline \multicolumn{3}{|c|}{ Case 3} & \multicolumn{3}{|c|}{ Case 4} \\
\hline & $\Delta \mathrm{R}$ & $\overline{\Delta \bar{R}}$ & & $\Delta \mathrm{R}$ & $\overline{\Delta \mathrm{R}}$ \\
\hline $\mathrm{E}$ & & $\times$ & E & & $x$ \\
\hline $\mathrm{C}$ & $\times$ & & $\mathrm{C}$ & & $x$ \\
\hline \multicolumn{6}{|l|}{ Inferences: } \\
\hline Case 1: & \multicolumn{5}{|c|}{$\begin{array}{l}\text { (1) } E \text { is sufficient; } \\
\text { (2) } E \text { is necessary; } \\
\therefore E \text { is causal for } R \text {. }\end{array}$} \\
\hline Case 2: & \multicolumn{5}{|c|}{$\begin{array}{l}\text { (1) } E \text { is sufficient but not necessary; } \\
\text { (2) } \mathrm{C} \text { is sufficient but not necessary; } \\
\therefore \text { Either } E \text { or } C \text { is sufficient to produce } R \text {. }\end{array}$} \\
\hline Case 3: & \multicolumn{5}{|c|}{$\begin{array}{l}\text { (1) } E \text { is not sufficient and is not necessary; } \\
\text { (2) } \mathrm{C} \text { is sufficient and necessary; } \\
\therefore \mathrm{C} \text { is causal for } \mathrm{R} \text { (but } \mathrm{C} \text { is a complex set } \\
\text { of variables). }\end{array}$} \\
\hline Case 4: & \multicolumn{5}{|c|}{$\begin{array}{l}\text { (1) } E \text { is not sufficient; } \\
\text { (2) } C \text { is not sufficient; } \\
\therefore \text { Neither } E \text { nor } C \text { have causal efficacy. }\end{array}$} \\
\hline
\end{tabular}

Analysis of Effects in E/C Designs plied to positive results obtained with both the experimental and the control treatments, as exemplified by Case 2 .

Negative evidence. As can be seen from the analysis in Table 1, the results in Case 3 and in Case 4, in which the experimental treatment has led to no change or no learning, are again uninterpretable in terms of attributing the results to an identified factor. Clearly, in Case 4, one cannot attribute the result to the experimental factor unambiguously, because both treatments have led to no change in the response or criterion variable. In Case 3, it appears as if the experimental factor has interfered with the change observed in the criterion response in the control condition. This, however, is a misinterpretation, because the control treatment is always developed with the intent of excluding the effective causal condition. Thus, the change observed in the control treatment condition is uninterpretable, because the control treatment condition includes an indefinite number of variables roughly classified into boundary and extraneous variables. As in Case 2, the efficacy of the control treatment in inducing a change in the criterion response variable renders uninterpretable the effect of the experimental treatment (in this case blocking), because the sufficient factor-the control treatment-can induce either sensitization or conditioning in the context of a specific learning experiment (see the discussion below of the effects of a nonneutral baseline in connection with one-trial learning). It is, then, not clear whether the blocking affects sensitization or learning. Thus, Case 3 is also uninterpretable. In summary, it is apparent that in Cases 2 and 3, the E/C design does not allow attribution of an observed change (e.g., an acquisition of a response to a stimulus). An issue of no change in Cases $\mathbf{3}$ and 4 is also uninterpretable. Mill's (1843) inductive method of differences can be properly applied to the results of Case 1 of Table 1 but not to Cases 2,3 , or 4 . It is obvious from this analysis that negative data, on the basis of an inductive logic analysis (i.e., an application of Mill's method of differences to the analysis of E/C design results), are shown independently of Grunbaum's argument that they cannot be attributed to the experimental factor manipulated in an $\mathrm{E} / \mathrm{C}$ design or to any hypothesis or law being tested through this manipulation.

Type II negative data. Cases 3 and 4 of Table 1 may be seen as Type I negative data. Their common feature is that the negative data-that is, the lack of an observed change due to the experimental treatment-cannot be attributed to a known factor (Case 4) or is uninterpretable (Case 3 ) in connection with an adequate $\mathrm{E} / \mathrm{C}$ design experiment in learning. To be able to attribute negative data to a known factor, one must invert Case 1 of the $\mathrm{E} / \mathrm{C}$ design by including in the experimental treatment an identified factor that can impede a change in the criterion variable (e.g., acquisition of conditioned response); when it is excluded from the control treatment, the control treatment should incorporate known factors sufficient to bring about a change in the criterion response variable (e.g., acquisition of a conditioned response). Two examples of 
Type II negative data are those observed in stimulusblocking experiments (Kamin, 1969) and in backward masking (Wright, 1964). In stimulus-blocking experiments, prior association of Stimulus A to a US will block a similar association of Stimulus B when Stimuli A and $B$ are compounded in the second phase of this type of an experiment, as compared with a control treatment in which Stimulus A is compounded with Stimulus B without prior Stimulus A association with the selected US. The control group of such experiments will typically show association of Stimulus B with the US, in contrast to the failure of such an association in the experimental group. As in Case 1, here the negative data can be attributed to a known factor. Similarly, in backward masking, a more intense white-noise stimulus, when it trails the presentation of a pure tone stimulus (within the narrow-bandwidth whitenoise frequency spectrum) by $125 \mathrm{msec}$ or less, will block detection of the first stimulus. When, in the control group, the white-noise stimulus is beyond the $125-\mathrm{msec}$ interstimulus interval, it will not impede its detection. To attribute negative data to a selected causally efficacious factor (e.g., a biological constraint factor), the pattern of results must be that of the Type II negative data described above. It should be clear, however, that a causal factor (e.g., a biological constraint factor) cannot be inferred from Type I negative data, given the correctness of the preceding analysis.

\section{Unexpected Failures of Conditioning and General-Process Learning Laws}

The first category of evidence on which inferences of biological constraints were based was the case of repeated observations of failure to learn in rat discrete leverpress discriminative avoidance studies (Bolles, 1970; D'Amato \& Schiff, 1964; Seligman, 1970). Related research had shown that this was not a problem of an inadequate CS, for numerous audiovisual stimuli have been used successfully in discriminative shuttle-avoidance tasks (Brush, 1966); nor was it a problem of an ineffective US (unconditioned or reinforcing stimulus), since electric shock has routinely been effective in discriminative shuttleavoidance tasks (Brush, 1966). Instead, according to Schwartz (1974), the problem was one of association. Finally, the failure to learn, if genuine, obviously demonstrated an exception to the law of acquisition (and that of equipotentiality); and true laws of science, being universal statements, do not permit exceptions. ${ }^{1}$

Applied to the observations of failure in discrete leverpress discriminative avoidance studies, Grunbaum's model allows two conclusions: (1) that the law of acquisition (or that of equipotentiality) was falsified; or (2) that one or more of the assumptions underlying the experimental tests were false (e.g., there was an improper choice of parameters). Berger, as reported in Berger (1969) and in Berger and Brush (1975), developed a successful rat leverpress discriminative avoidance paradigm showing normal acquisition rates, by using an intermittent shock stimulus, a long CS-US interval, and an added safety sig- nal at the end. Perhaps the added safety signal disrupted the incompatible responses of freezing and escape responding, and the long interstimulus interval permitted the animal to show the learned association. Modifying the barpress avoidance procedure by adding a safety signal did not alter the task, as it might be argued (and thus throw into question the validity of the observed results and interpretation), because the added safety signal merely reinstated the safety indicator cues normally present in the runway avoidance paradigm.

These successful observations and others (Domjan, 1983, p. 229; Moore, 1973) support the second of the two conclusions above. They demonstrate that the identification of proper learning test parameters in any empirical test of a law of learning can differentiate cases of failure from cases of success. Thus, negative data, as shown above empirically in the form of the failure to condition, are not sufficient to compel an inference of a biological constraint, for there remains, according to Grunbaum's analysis, the unresolved issue of adequacy of the particular choice of parameters. Furthermore, response-defined concepts, such as "preparedness" (Seligman, 1970) and "species-specific defense reactions-SSDRs" (Bolles, 1975), are not adequate sources of explanation for failures to condition, because any test of a prediction from such concepts necessarily involves circular reasoning. Bolles (1975) has, however, made attempts to define the SSDR concept in nonresponse terms, so this criticism may not be totally justified.

\section{Inferences of Biological Constraints Based on Rapid One-Trial Learning Paradigms}

The apparent rapidity of association with taste cues in taste-aversion studies with hitherto implausible CS-US intervals of 1 to $1.5 \mathrm{~h}$ (Garcia, Ervin, \& Koelling, 1976) is the second type of evidence for biological constraint factors (in this case operating to facilitate learning). General-process laws were again shown to have limited generality, for they could not account for the rapidity of one-trial conditioning or for the wide bandwidth of the effective CS-US interval (Garcia, McGowan, \& Green, 1972; Seligman \& Hager, 1972).

Although recent assessments of taste-aversion observations tend to incorporate taste-aversion phenomena within existing general-process laws and theoretical frameworks (Logue, 1979; Schwartz, 1974), there is one fundamental unaddressed problem specific to one-trial or rapid learning; it opens the door to a different interpretation. Viewed in terms of the most general case, the problem exists not only for taste aversion, but for all onetrial or rapid-learning paradigms.

Figure 1 exhibits three different types of acquisition observations schematically. Given the current codification of associative learning effects as being determined by the magnitude of the E/C contrast (Gormezano, 1966; Gormezano \& Kehoe, 1975), an uncritical examination will allow all three examples shown in Figure 1 (Panels A, $B$, and $C$ ) to be adequate demonstrations of learning (as- 
A

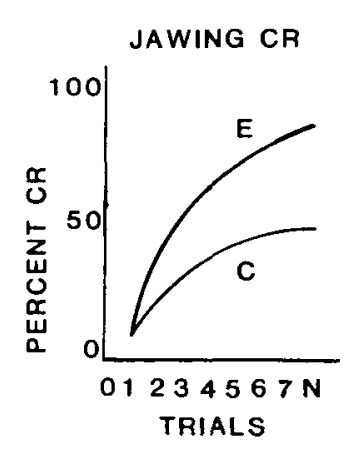

$B$

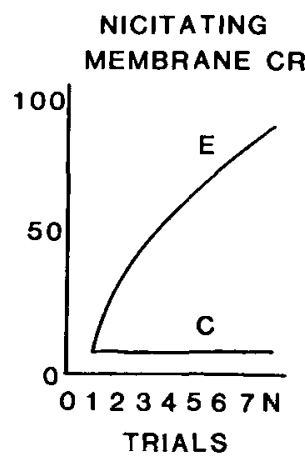

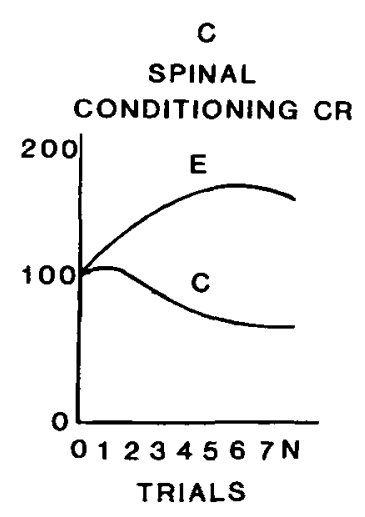

ACQUISITION

Figure 1. Acquisition and control treatment effects in three different classical conditioning preparations.

suming here the satisfaction of statistical analysis requirements for the demonstration of a difference). It can be argued that each $\mathrm{E} / \mathrm{C}$ contrast shown can justify an inference of associative learning. However, a closer look will reveal acquisition (observed increase in response measurement) as occurring in both the experimental and the control treatment groups in the first example (Panel A), but only in the experimentally treated groups in the second and third examples (Panels B and C). Empirically studied phenomena that illustrate these kinds of effects respectively are: (1) rabbit jawing response (Gormezano, 1972; Sheafor, 1975); (2) rabbit nictitating membrane response (Gormezano, 1972); and (3) spinal conditioning (Durkovic, 1975, 1983, 1985).

The results in Panels B and C of Figure 1 correspond to Case 1 of Table 1 . In these instances, the inference of associative effects is warranted, because the baselines show an absence of effect directionally identical to that of the experimentally treated group-that is, the baseline in these instances shows either no change with trials or a decline in the opposite direction. However, the results in Panel A correspond to Case 2 of Table 1. The acquisition effects of both the experimental and control treatments are directionally identical, differing only in degree. As might be anticipated from the earlier analysis of $E / C$ design results shown in Table 1 , the Panel A results permit two specific types of interpretation: (1) that associative effects are being demonstrated over and above the nonassociative effects induced by the control treatment procedure (this is the conventional interpretation); or (2) that nonassociative effects are being demonstrated in both groups, because the control treatment paradigm embedded in the experimental treatment paradigm (see Formula 2 above) is sufficient to induce acquisition of the target response to the CS (this is the alternative interpretation). Thus, observed quantitative differences may reflect associative effects or, alternately, differential potentiation of nonassociative effects-with the experimental treatment being more effective. Although through further testing (i.e., extinction, stimulus generalization, or second-order conditioning tests) these alternative interpretations can be distinguished, clearly the quantitative difference between experimental and control group treatment effects in instances where both treatments result in increasing acquisition curves does not by itself imply that the one is due to associative effects and the other to nonassociative ones. A further complicating factor is that nonassociative effects may also be sensitive to CS-US interval effects (the earlier, traditional defining characteristic of associative effects). For example, there appears to be a genuine issue as to the associative-nonassociative nature of CS-US interval effects in taste-aversion studies (Domjan, 1980; Mitchell, Scott, \& Mitchell, 1977).

As seen from the analysis above, one-trial or rapid learning presents the problem that control-treatment onetrial observations give no indication of the kind of baseline one has in terms of the examples shown in Figure 1. If the baseline rises significantly with repeated exposure, as in Panel A of Figure 1, then regardless of whether or not one observes a significant $\mathrm{E} / \mathrm{C}$ contrast, one cannot decide without extensive stimulus generalization, retention, and even second-order conditioning tests whether the acquisition observed with the experimental treatment is due to associative or nonassociative factors. Without being circular, one cannot designate the effects of paired CS-US treatment as associative and those of the unpaired treatments as nonassociative, unless one employs the suggested independent tests. Thus, rapid learning observations do not by themselves imply the operation of biological constraint mechanisms, but they do strongly support the need to investigate the process of sensitization and its possible contribution to observed conditioning effects, as a source of explanation for rapid conditioning in place of biological constraint frameworks. The neurosubstrate findings of Kandel and associates (Hawkins \& Kandel, 1984; Kandel \& Schwartz, 1982) demonstrate that USinduced sensitization is the core process in conditioning. 
This observation suggests the possible importance and functional role of sensitization as a contributing factor in rapid learning and as a clue to a direct relationship between behavioral indices of sensitization and the width of the effective interstimulus interval across the different types of conditioning preparations. Again, inferences of biological constraints based on one-trial or rapid learning are not uniquely supported by such data.

\section{Interaction or Crossover Paradigms as a Methodological Basis for Biological Constraints}

Perhaps the most elaborate grounds for postulating biological constraints beyond the two previous categories of evidence are the observations of stimulus-response interactions that have resulted in either retarded or accelerated learning. The prototypical findings of Garcia and Koelling (1966) illustrate the point. Audiovisual cues were associated to a shock-induced aversion indicator response, but not to an illness-induced aversion. Similarly, taste stimuli were associated to an illness-induced aversion indicator response but not to a shock-induced aversion. The two types of CSs were presented simultaneously to rats in a taste-aversion paradigm. Thus, "bright-noisy" water was associated with shock, whereas "tasty" water was associated with an illness-induced aversion. "Brightnoisy" water was not associated with an illness-induced aversion, and similarly, taste stimuli were not associated with a shock-induced aversion (see Berk \& Miller, 1978, and Best, Best, \& Mickley, 1973, for alternative results and interpretation).

The earliest interpretation of the Garcia-Koelling effect was that it demonstrated a functional, evolutionary adaptive selectivity in stimulus-response associations (Garcia, McGowan, \& Green, 1972). One thought was that such selective associations mirror the causal nexus of environmental events more closely; poisoning, for example, is more likely to be caused by ingestional stimuli than by exteroceptive stimuli, and escape responding by exteroceptive stimuli rather than ingestional ones (see Mackintosh, 1983, p. 221). Subsequent demonstrations of the Garcia-Koelling effect in different and more completely controlled experiments (e.g., Domjan \& Wilson, 1972; Miller \& Domjan, 1981) was thought to point to special categories of stimuli that could be rapidly conditioned to toxicosis effects on the one hand, according to the principles of relevance and belongingness, and, on the other hand, to other categories that could not be conditioned at all. The provision of a taxonomy of stimulus and response categories, moreover, provided a noncircular operational definition of biological constraint factors and a means of controlling the outcome as well. A more concrete taxonomic scheme relating classes of stimuli to response categories is presented by Garcia, Lasiter, Bermudez-Rattoni, and Deems (1985). However, the lack of adequate experimental identification and manipulation of biological constraint factors that characterize stimuli and response categories in terms of the rubric of relevance or belongingness leaves open the door to task-specific factor interpretations of these same crossover results. For example, one can hypothesize an early developmental learning history in which an animal associates ingestion with physical illness, and locomotion with escape from interanimal aversive stimulation. This early learning could then function as a blocking mechanism with respect to any crossover associations, in the manner suggested by $\mathrm{Ka}$ min's (1969) stimulus-blocking experiments. Such a hypothesis can be tested by a developmental study of crossover effects.

The argument as presented above by the "crossover" results is more sophisticated than that in the earlier types of evidence, because the positive cases of learning show adequacy of the CSs, CRs, and the reinforcer stimuli in a particular test case; thus, they demonstrate paradigm sensitivity (e.g., effective stimulus, response, and reinforcer parameters). ${ }^{2}$ As a consequence, the observed failures in these crossover combinations, together with the positive instances, are assumed to imply the operation of underlying biological constraint factors. Nonetheless, the negative evidence of retarded or no learning obtained with crossover paradigms is still not necessarily compelling evidence, whether taken in the terms of the Grunbaum analysis above or because it is Type I negative evidence that exemplifies Case 4 in Table 1 . The evidence would be compelling if it could be shown, additionally, to be a result of the operation of a specific mechanism. Independent establishment of a causal mechanism, as with Type II negative evidence (as in the case of the prior learning in the stimulus-blocking paradigm-Kamin, 1969), would then have placed inferences of biological constraints on sufficient grounds. Subsequent investigations with the crossover paradigm, however, failed to take this necessary next step, and instead it was concluded that the failure of learning observations and the implied inconsistency with a general-process law (here equipotentiality) were sufficient to infer the presence of a biological constraint.

Retarded learning or null results (Type I negative evidence), as already indicated, allow according to Grunbaum's analysis an alternative interpretation of the same results-namely, that such results may be produced by task-specific factors and not by species-specific biological constraint factors. Thus, subsequent experimental investigations have demonstrated that taste cues are effective in the induction of aversion learning to shock if the CS-US interval can be appropriately adjusted to the temporal characteristics of taste cues (Krane \& Wagner, 1975), and that exteroceptive cues can be conditioned to ingestional USs (Delamater, LoLordo, \& Berridge, 1986; Krane, 1980) if an appropriate CR measurement is selected or if shock-site is appropriate (Delamater \& Tait, 1987). Collectively, these subsequent observations show that task-specific interpretations based on manipulation of general-process factors can provide an alternative interpretation of the retarded-learning observations found with crossover paradigms. Once more, the evidence for biological constraint mechanisms is not compelling. The tie to stimulus factors such as "relevance" and/or "belongingness" does not seem to show the kind of general- 
ity that might be expected should such factors be biologically based. At best, the evidence points to constraint phenomena that may or may not be biologically based. Thus, conclusions made on the basis of crossover paradigms about biological constraint mechanisms exceed the data at hand, because the further step of identifying and manipulating a biological constraint factor according to the inverse of the Case 1 paradigm of Table 1 (i.e., Type II negative data) is never taken. That such a step has in some instances been taken in other contexts is indicated below.

\section{Predictions of Biological Constraint Effects from Ethological-Ecological Approaches to Learning}

Perhaps the best support for utilizing ethologicalecological databases to predict a biological constraint framework is that it makes possible unique predictions of retarded or accelerated learning that cannot otherwise be made from general-process laws. Such predictions are, however, limited by the need to translate ethologicalecological factors into causal, identifiable factors amenable to laboratory experimentation (e.g., Daly et al., 1982). Another limitation is the need to reduce any factor regardless of origin into one that could affect classical and/or operant conditioning mechanisms. The translation of ethological-ecological, correlational factors into causal identifiable factors (i.e., factors that with an E/C design can be shown to be necessary and sufficient to show an impedance or an acceleration in learning) that are amenable to laboratory manipulations is difficult, but not necessarily impossible (see Domjan \& Galef, 1983, p. 159). Current attempts in this direction utilize taxonomically based systems-put simply, programmatic frameworks-as sources of testable predictions. Rozin and Kalat (1971) presented an adaptive-evolutionary framework in the study of learning behavior, based on the assumption that situation-specific learning mechanisms have developed to become specialized in different species. To account for unexpected failures of learning, rapid learning, and crossover phenomena, these investigators postulate stimulus-selection principles such as (1) a noveltyfamiliarity dimension (better learning is attributed to novel stimuli), and (2) a "belongingness" dimension (better learning is attributed to CS-US stimuli that belong together). Although such principles are supported by positive results of interaction or crossover paradigms, the tie to specific stimulus characteristics is nonetheless vague. Appeals here to concepts of evolutionary adaptation and survival are at best heuristic devices (Rozin \& Kalat, 1971); at worst, they are purely post-hoc story-telling accounts. The critical ties to stimulus characteristics that when present will result in a failure of learning or in accelerated learning and when absent will result in a normal or expected form of learning have not been specified. This type of additional evidence (Type II negative evidence) is critical for any inference of biological constraint factors.

Attempts in this direction are not lacking, however. Timberlake and associates (Timberlake, 1983, p. 193), working from a behavioral systems model, predicted that the response conditioned through CS-US pairings or contingencies depends not on the US and US-induced response alone but on the behavioral repertoire elicited by the CS and US. A modular organization of stimuli and responses was assumed to exist, which, depending on the ecological task confronting the animal, could gain control of behavior. Thus, in one experiment, two experimental treatments separated the subjects: in the first, the subject was presented with a mature conspecific adult rat immediately before the presentation of food; in the second, the subject was presented with a young pup. The generalprocess learning law predicted that both types of CSanimals would elicit food-related responses; the behavioral systems approach predicted that young pups would show more "sociable" (approach type of) behavior toward the adult subjects, whereas the adult rats would not show such behavior toward a young pup. The background ecological assumption was that it is more efficient to follow an adult conspecific than a young pup in terms of food location efficiency. The results supported the prediction. Nonetheless, the story-telling character of this behavioral systems prediction is apparent from the fact of using a multidimensional CS (adults as opposed to rat pups). There could be many reasons why a rat pup would be more sociable toward an adult rat associated with the presence of food, and why an adult rat would fail to show similar behavior. For example, it is not clear how an adult rat CS is in any way equivalent to a pup CS, in terms of perceptual equivalence as stimuli to be associated with a food US. Yet, if the results were to be uniquely attributable to a food location efficiency factor, the stimuli needed to be equalized in terms of their salience, or minimally, in terms of their stimulus intensity values. Furthermore, the learning histories of adults and young pups are hardly equal. In the control-group treatment where associative responses are not expected, this might not be an important dimension, but in the experimental treatment results, where a comparison is made between two different treatments, such an inequality can perhaps account for the results. The weakness here is not in the behavioral systems approach, nor is it in the experimental design employed as it conforms with the Case 1 model of Table 1 ; the weakness lies in the tie of adults and young pups, functioning as Pavlovian CSs, to the correlational database of ethological-ecological observations-that is, the source of rules and generalizations for the biological constraints approach. The connection here involves mere storytelling, not assumption, hypothesis, and prediction based on rules of inference.

In contrast to this lack of operational explicitness, Weisinger, Parker, and Skorupski (1974) attempted to induce a biological constraint factor directly, by injection of formalin and insulin. Formalin in rats was assumed to induce a sodium appetite and insulin a reduction of blood sugar. Constraints in the learning of aversions to salt and to sugar solutions were expected to result. The results were consistent with the expectations. However, a replication study by Domjan and Levy (1977) showed 
that the failure to condition an aversion response was due to the weak sugar solution that served as the CS. Although the results were not replicated, the Weisinger et al. (1974) study is a model of the type of additional evidence (Type II negative evidence) needed beyond simple failures to condition, in order to compel an inference of a biological constraint.

The studies above illustrate the advantages as well as the pitfalls of the biological constraint approach to learning. Although unique predictions that went beyond general-process assumptions were possible in each case, and although these were amenable to experimental manipulation, the story-telling character of the one interpretation and the task-specific character of the results of the other are evident. The fourth type of evidence for biological constraints that operate as mechanisms to facilitate or to hinder learning, evidence that is based on unique predictions from biological-constraint approaches, is thus also not compelling.

\section{Concluding Comments}

The review above of the four types of evidence used to support inferences of biological constraints indicates that the evidence is insufficient to warrant inferences of biological constraints operating as mechanisms to hinder or to facilitate learning. This conclusion parallels that reached by Domjan (1983) in a case-by-case review. However, the present analysis identifies a core problem underlying such inferences. Current logic models of scientific explanation and prediction (Grunbaum, 1969) rule out making any compelling conclusions about tested hypotheses or laws on the basis of negative evidence, whether that evidence takes the form of failures to learn (Categories 1 and 2), or the form of opposing or unique types of evidence (Categories 3 and 4). Thus, the negative evidence in the four categories above does not compel a rejection of learning principles or laws tested, nor, collectively, of the general-process law approach. At the same time, this same negative evidence is not compelling for inferences of biological constraints as explanations of the categories of evidence reviewed. For negative evidence to be compelling as a ground for inferring the operation of a biological constraint, one additional step is necessary: namely, the use of the inverse $\mathrm{E} / \mathrm{C}$ paradigm with the Case 1 (Table 1) type of results--Type II negative data-so that the negative evidence observed can be causally attributed to specific biological constraint factors or mechanisms. The essential feature of Type II negative data is that while the experimental treatment includes the manipulated biological constraint factor that might be expected to block or retard learning, the control group treatment must feature stimulus treatment adequate to induce the learning behavior that the biological constraint factor is expected to block or retard. The wellcharacterized treatment and behavioral result of the control treatment then allows a clear interpretation of what is blocked or retarded by the experimental treatment, and of the factor to which this blocking or retardation can be attributed. The concrete example, as already indicated, is the stimulus-blocking paradigm (Kamin, 1969) or the backward-masking paradigm.

Interpreted in terms of Formula 1, in Type II negative data design the experimenter chooses an $A$ treatment that is known to be adequate to produce a positive behavioral result-that is, learning-but leaves the $\mathrm{X}$-factor out, whereas in the experimental treatment, the $\mathrm{X}$-factor is included along with the $A$ treatment and is sufficient to produce the negative results. Thus, Type II negative data represents the limiting case of Formula 1 where the effects of A treatment are known and interpretable in advance of a given test, and thus the interpretive disjunction between $X$ and $A$ when negative results are obtained is eliminated by eliminating the $A$ treatment as a source of explanation. Only in this way can negative evidence function adequately in demonstrations of biological constraints.

\section{REFERENCES}

BERGER, D. F. (1969). Alternative interpretation of the frustrative effect. Journal of Experimental Psychology, 81, 475-483.

BERGER, D. F., BRUSH, R. F. (1975). Rapid acquisition of discrete trial lever press avoidance: Effects of signal-shock interval. Journal of the Experimental Analysis of Behavior, 24, 227-239.

Bergmann, G. (1957). Science. Madison, WI: University of Wisconsin Press.

BeRK, A. M., \& Miller, R. R. (1978). LiCl-induced aversion to audiovisual cues as a function of response measure and CS-US interval. Behavioral Biology, 24, 158-208.

Best, P. J., Best, M. R., \& Mickley, A. (1973). Conditioned aversion to distinct environmental stimuli resulting from gastro-intestinal disease. Journal of Comparative \& Physiological Psychology, 85, 250-259.

BoLles, R. C. (1970). Species-specific defense reactions and avoidance learning. Psychological Review, 77, 32-48.

Bolles, R. C. (1975). Learning theory. New York: Holt, Rinehart \& Winston.

BRUSH, F. R. (1966). On the differences between animals that learn and do not learn to avoid electric shock. Psychonomic Science, 5, 123-124.

Daty, M., Rauschenberger, J., \& Behrends, P. (1982). Food aversion learning in kangaroo rats: A specialist-generalist comparison. Animal Learning \& Behavior, 10, 314-320.

D'Amato, M. R., \& Schiff, D. (1964). Long-term discriminative avoidance performance in the rat. Journal of Comparative \& Physiological Psychology, 57, 123-126.

Damianopoulos, E. N. (1987). Conditioning, attention and the CS US interval: A theoretical statement of relations. Pavlovian Joumal of Biological Science, 22, 16-29.

Damianopoulos, E. N. (1982). Necessary and sufficient factors in classical conditioning. Pavlovian Journal of Biological Science, 17, 215-229.

Delamater, A. R., Lolordo, V. M., \& Berridge, K. C. (1986). Control of fluid palatability by exteroceptive Pavlovian signals. Joumal of Experimental Psychology: Animal Behavior Processes, 12, 143-152.

Delamater, A. R., \& TaIT, R. (1987). Taste aversion conditioning with shock but not with $\mathrm{LiCl}$ are sensitive to anxiolytic effects of chlordiazepoxide. Proceedings and Abstracts of the Annual Meetings of the EPA, 55, 56.

DOMJAN, M. (1980). Ingestional aversion learning: Unique and general processes. In J. S. Rosenblatt, R. A. Hinde, C. Beer, \& M. C. Busnel (Eds.). Advances in the study of behavior (Vol. 11, pp. 275-336). New York: Academic Press.

Domjan, M. (1983). Biological constraints on instrumental and classical conditioning: Implications for general-process theory. In G. $\mathbf{H}$. Bower \& J. Spence (Eds.), The psychology of learning and motivation (Vol. 17, pp. 215-277). New York: Academic Press. 
Domun, M. (1985). Cue-consequence specificity and long-delay learning revisited. Annals of the New York Academy of Sciences, 443, 54-66.

Domjan, M. , \& Galef, B. J., JR. (1983). Biological constraints on instrumental and classical conditioning: Retrospect and prospect. Animal Learning \& Behavior, 11, 151-161.

Domuan, M. , Levy, C. J. (1977). Taste aversion conditioned by the aversiveness of insulin and formalin. Role of CS-specificity. Journal of Experimental Psychology: Animal Behavior Processes, 3, 119-131.

Domjan, M., \& Wilson, N. E. (1972). Specificity of cue to consequence in aversion learning in the rat. Psychonomic Science, 26, 143-145.

Durkovic, R. G. (1975). Classical conditioning, sensitization and habituation in the spinal cat. Physiology \& Behavior, 14, 297-304.

Durkovic, R. G. (1983). Classical conditioning of the flexion reflex facilitation in the spinal cat: Features of the reflex circuitry. Neuroscience Letters, 39, 155-160.

Durkovic, R. G. (1985). Retention of classically conditioned reflex facilitation in the spinal cat. Behavioral Neural Biology, 43, 12-20.

FurEDY, J. J. (1978). Conceptual analyses and method in psychology. In J. P. Suttcliffe (Ed.), Essays in honor of W. M. ONeill. Sydney: University of Sydney Press.

Garcia, J., Ervin, F. R., \& Koelling, R. A. (1966). Learning with prolonged delay of reinforcement. Psychonomic Science, 5, 121-122.

Garcia, J., \& KoElling, R. A. (1966). Relation of cue to consequence in avoidance learning. Psychonomic Science, 4, 123-124.

Garcia, J., Lasiter, P. S., Bermudez-Rattoni, F., \& Deems, D. A (1985). A general theory of aversion learning. Annals of the New York Academy of Sciences, 443, 8-21.

Garcia, J., McGowan, B. K., \& Green, K. R. (1972). Biological constraints in conditioning. In A. H. Black \& W. R. Prokasy (Eds.), Classical conditioning (Vol. 2, pp. 3-27). New York: Appleton-CenturyCrofts.

Gormezano, I. (1966). Classical conditioning. In J. B. Sidowski (Ed.), Experimental methods and instrumentation in psychology (pp. 385420). New York: McGraw-Hill.

GORMEZANo, I. (1972). Investigation of defense and reward conditioning in the rabbit. In A. H. Black \& W. F. Prokasy (Eds.), Classical conditioning (Vol. 2, pp. 151-181). New York: Appleton-Century-Crofts.

Gormezano, I., \& Kehoe, E. J. (1975). Classical conditioning: Some methodological issues. In W. K. Estes (Ed.), Handbook of learning and cognitive processes (Vol. 2, pp. 143-179). Hillsdale, NJ: Erlbaum.

Grunbaum, A. (1969). Can we ascertain the falsity of scientific hypotheses? In E. Nagel, S. Bromberger, \& A. Grunbaum (Eds.), Observation and theory in science (pp. 271-301). Baltimore: Johns Hopkins University Press.

HARRE, R. (1970). The principles of scientific thinking. Chicago: University of Chicago Press.

HAWKINS, R. D., \& KANDEL, E. R. (1984). Is there a cell-biological alphabet for simple forms of learning? Psychological Review, 91 , 375-391.

HEMPEL, C. G. (1963). Explanation and prediction by covering laws. In B. Baumrin (Ed.), Philosophy of science: The Delaware Seminar (Vol. 1, pp. 107-133). New York: Wiley.

HESSE, M. (1974). The structure of scientific inference. Berkeley and Los Angeles: University of California Press.

Kamin, L. (1969). Predictability, surprise, attention and conditioning. In B. A. Campbell \& R. M. Church (Eds.), Punishment and aversive behavior (pp. 279-296). New York: Appleton-Century-Crofts.

KANDEL, E. R., \&ChWARTZ, J. H. (1982). Molecular biology of learning: Modulation of transmitter release. Science, 218, 433-443.

KRANE, R. V. (1980). Toxiphobia conditioning with exteroceptive cues. Animal Learning \& Behavior, 8, 513-523.

KRANE, R. V., \& WAGNER, A. R. (1975). Taste-aversion learning with a delayed shock US: Implications for "the generality of the laws of learning." Journal of Comparative \& Physiological Psychology, 88, 882-889.
KuHN, R. S. (1962). The structure of scientific revolutions. Chicago: University of Chicago Press.

LoguE, A. W. (1979). Taste aversion and the generality of the laws of learning. Psychological Bulletin, 86, 276-296.

Mackintosh, N. J. (1983). Conditioning, attention, and associative learning. New York: Oxford University Press.

McGuigan, F. J. (1983). Experimental psychology: Methods of research. Englewood Cliffs, NJ: Prentice-Hall.

MiLL, J. S. (1843). A system of logic. London: J. D. Parker Publishers.

Miller, V., \& Domjan, M. (1981). Specificity of cue to consequence in aversion learning in the rat: Control for US-induced differential orientations. Animal Learning \& Behavior, 9, 339-345.

Mitchell, D., Scott, D. W., \& Mitchell, L. K. (1977). Attenuated and enhanced neophobia in the taste-aversion "delay of reinforcement" effect. Animal Learning \& Behavior, 5, 99-102.

Moore, B. R. (1973). The role of directed Pavlovian reactions to simple instrumental learning in the pigeon. In R. A. Hinde \& J. StevensonHinde (Eds.), Constraints on learning (pp. 159-186). New York: Academic Press.

Rozin, R., \& Kalat, J. W. (1971). Specific hungers and poison avoidance as adaptive specializations of learning. Psychological Review, 78, 459-486.

SchWARTZ, P. J. (1974). On going back to nature: A review of Seligman's and Hager's Biological boundaries of learning. Journal of the Experimental Analysis of Behavior, 21, 183-184.

Seligman, M. E. (1970). On the generality of the laws of learning. Psychological Review, 77, 406-418.

Seligman, M. E. P., \& Hager, J. L. (1972). Biological boundaries of learning. New York: Appleton-Century-Crofts.

SHEAFOr, P. J. (1975). "Pseudoconditioning" of jaw movement of the rabbit reflects associations conditioned to contextual stimuli. Journal of Experimental Psychology: Animal Behavior Processes, 1, 245-260.

SHETTLEWORTH, S. J. (1972). Constraints on learning. In D. S. Lehrman, R. A. Hinde, \& E. Shaw (Eds.), Advances in the study of behavior (Vol. 4, pp. 1-68). New York: Academic Press.

TimBerLAKE, W. (1983). The functional organization of appetitive behavior: Behavior systems and learning. In M. D. Zeiler \& P. Harzem (Eds.), Advances in the analysis of behavior (Vol. 3, pp. 177221). New York: Wiley.

Timberlake, W., \& Grant, D. L. (1975). Auto-shaping in rats to the presentation of another rat predicting food. Science, 190, 690-692.

Weisinger, R. S., Parker, L. F., \& Skorupski, J. D. (1974). Conditioned taste aversions and specific need states in the rat. Journal of Comparative \& Physiological Psychology, 87, 655-660.

WRIGHT, H. S. (1964). Summation and backward masking. Journal of the Acoustical Society of America, 36, 923-932.

\section{NOTES}

1. The concept of "boundary" conditions, which would allow "exceptions," does not apply here, since boundary conditions define a closed system of interacting variables. In psychology, variables interact in open systems of variables (Bergman, 1957). Background variables with which selected experimental variables interact are rarely, if ever, identified. Control treatment procedures are, therefore, based on the rationale of randomizing or holding constant the effects of such variables.

2. When independent evidence exists regarding dependent variable sensitivity to test conditions, then and only then can one consider a failure to replicate as disconfirming evidence of a general-process law (Furedy, 1978).

(Manuscript received July 15, 1988; revision accepted for publication August 5,1988 .) 